\title{
AUTOMATION OF A 3D PRINTED HAND PROSTHE- SIS WITH ARDUINO APPLICATION
}

\author{
Cristoffer Lincon de Oliveira ${ }^{1}$
}

Summary:This study deals with the analysis of an automation method for a functional hand prosthesis. The possibility of adapting to a prosthesis manufactured by the $3 \mathrm{D}$ printing process that originally moved mechanically was evaluated, with the aim of automating this artifact and making it functional. It was idealized to develop an automation system for this type of prosthesis, so that obtaining by the additive manufacturing method is quick and easy, and is suitable to receive the customized automation system and accessible to users. After all the modeling and confection processes were completed, the Arduino ${ }^{\circledR}$ software with $\mathrm{C} / \mathrm{C}++$ language was used, developing the programming for the prosthesis. The program was created with the function of performing reading by electromyography sensors (EGM), which has the function of capturing the action potentials produced by muscle fibers of the arm and its contraction, and sending this captured data to the Arduino ${ }^{\circledR}$ board, which then sends a signal to the micro motors, responsible for moving the arms. fingers. It was possible to manufacture the prosthesis, as planned and pro-

1 Centro Universitário UniOpet

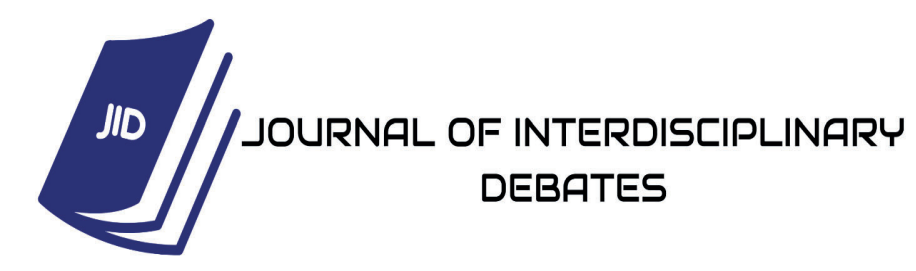


jected on a computer design platform, performing automation, testing the degree of movement qualitatively. Satisfactory results were obtained in its production and adequacy of automation at the prototype level. as planned and projected on a computational design platform, performing automation, testing the degree of movement qualitatively. Satisfactory results were obtained in its production and adequacy of automation at the prototype level. as planned and projected on a computational design platform, performing automation, testing the degree of movement qualitatively. Satisfactory results were obtained in its production and adequacy of automation at the prototype level.

Keywords: Prosthesis; Arduino; Additive manufacturing; Automation

\section{INTRODUCTION}

Prostheses are objects that have been used for centuries to replace limbs or parts of these in the human body, with evidence of their use since the pre-Christian era. A prosthesis aims to assume the functions of the amputated or malformed limb. People with physical limitations often find it difficult to integrate into society due to the difficulty of performing their daily tasks, which is why many of them seek accessible prostheses as a way to have more autonomy (Aquino and Volpini, 2018).

Scientists try to develop mechanisms capable of serving the most diverse purposes, studies are being carried out in various fields with the intention of reproducing the motor functions of living beings. In this context, faced with research on the use of 
prostheses, the problem arises: how to make the prosthesis more accessible to people who have suffered amputations or who have poor training?

Prostheses equipped with bionic movement can be excessively expensive, while the most accessible ones do not have satisfactory mobility. Another aspect is the complexity in building a prosthesis prepared to receive automation, which consists of the multidisciplinarity of the tasks involved, contributing to remove the use of technology from social reach.

The development of an automation method associated with additive manufacturing for hand prostheses can make this type of resource more accessible, with the procedures followed for carrying out activities being disseminated, democratizing technology(Stoppa and Mendes,
2016).

For the manufacture of the aforementioned prosthesis, the capacity of small engines will be evaluated and the manufacture of the artifact, which must be done on a $3 \mathrm{D}$ printer in the robotics laboratory of Uniopet. The material used will be PLA (Poliacid Lactic), as it is a biodegradable thermoplastic polymeric material derived from renewable sources, which is widely used in making biomaterials (Franchetti and Marconato, 2006).

In addition to making the hand prosthesis, we intend to evaluate an automation method applicable to the type of prosthesis described and manufactured, so that parameters are generated to proceed in different cases that are similar to this study.

Considering the need to define a method to automate a low-cost hand prosthesis, made

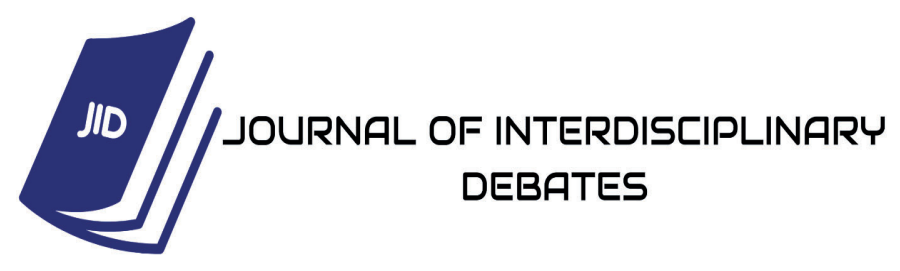


in a 3D printer, using Arduino ${ }^{\circledR}$ programming, the objectives of this work are described as:

The) Manufacture a passive automation prosthesis;

B) Program and apply automation system in Arduino ${ }^{\circledR}$ in the prosthesis;

ç) Evaluate the applicability of the method in similar situations.

\section{MATERIAL AND METHODS}

For the development of this project, from the modeling, through the manufacture of the hand prosthesis, to the completion of the tests, the steps described below were followed along with the related materials.

First it was necessary to obtain a morphological model of a hand. The three-dimensional image file was generated in the Autodesk Fusion 360® software, from a pre-existing model of the right member. The employee who supplied the original model did not participate in the present automation work, being only interested in the morphological adjustments of the model, that is, to give freedom of mechanical movement.

The process of transforming the three-dimensional model into polymeric pieces requires the segmentation of this model in layers (Foggiatto and Silva, 2017), applying the program functionO Simplify3D $\AA$, which transforms the solid part into the number of necessary and sufficient layers to enable the reading of the 3D printer and the best material deposition rate for that application. The image was converted to STL format (Standard Triangle Language), for transfer to the printing machine. The manufacturing of the components by additive manufacturing was car-

\section{N1D}


ried out in the robotics laboratory of Centro Universitário UniOpet, using a printer of its own manufacture and powered by PLA filament of $1.75 \mathrm{~mm}$ in diameter.

The motors used in this project are of the micro motor type, in a total of four units, each assembled with a metal reduction box whose transmission ratio is 50: 1, and a 3mm "D" shaped shaft. The possible operating voltage is $3 \mathrm{~V}$ to $12 \mathrm{~V}$, and the rated working speed is $0.1 \mathrm{~s} / 60^{\circ}$, with the capacity to produce $1.40 \mathrm{kgf}$. $\mathrm{cm}$ of torque at $6 \mathrm{~V}$. The external measurements of these actuators $(35 \mathrm{~mm} \times 10 \mathrm{~mm} \times 12 \mathrm{~mm})$ were previously taken in order to accurately design the housings in the prosthesis structure.

For the tendon function, polyamide (nylon) threads from the manufacturer KastKing Rubicon, with a nominal resistance of $22.67 \mathrm{~kg}$, were used, and for the relaxation function, each finger is provided with a small steel spring.

An Arduino Uno ${ }^{\circledR}$ board was used to recognize the electrical signals from the muscles and control movement. The programming was carried out in Java language, using the Arduino ${ }^{\circledR}$ system's own application. The command signal, which is the input signal, is obtained by a pair of EGM Muscle Sensor v3 sensors, with self-adhesive electrodes for the skin and connected directly to the plate. With the programming in progress, some basic tests were carried out to check the input and output signals and the behavior of the components integrated into the system.

The assembly of the structure and components was carried out manually with the aid of simple tools such as pliers, screwdrivers and soldering iron. 
ISSN: 2675-469X

Vol. 02 - n 02 - ano 2021

Editora Acadêmica Periodicojs

After assembly, functional tests

and mechanical adjustments and

programming adjustments were carried out.
The planning for the

execution of the project took pla-

ce in the order that presents the

flowchart illustrated in Figure 1.
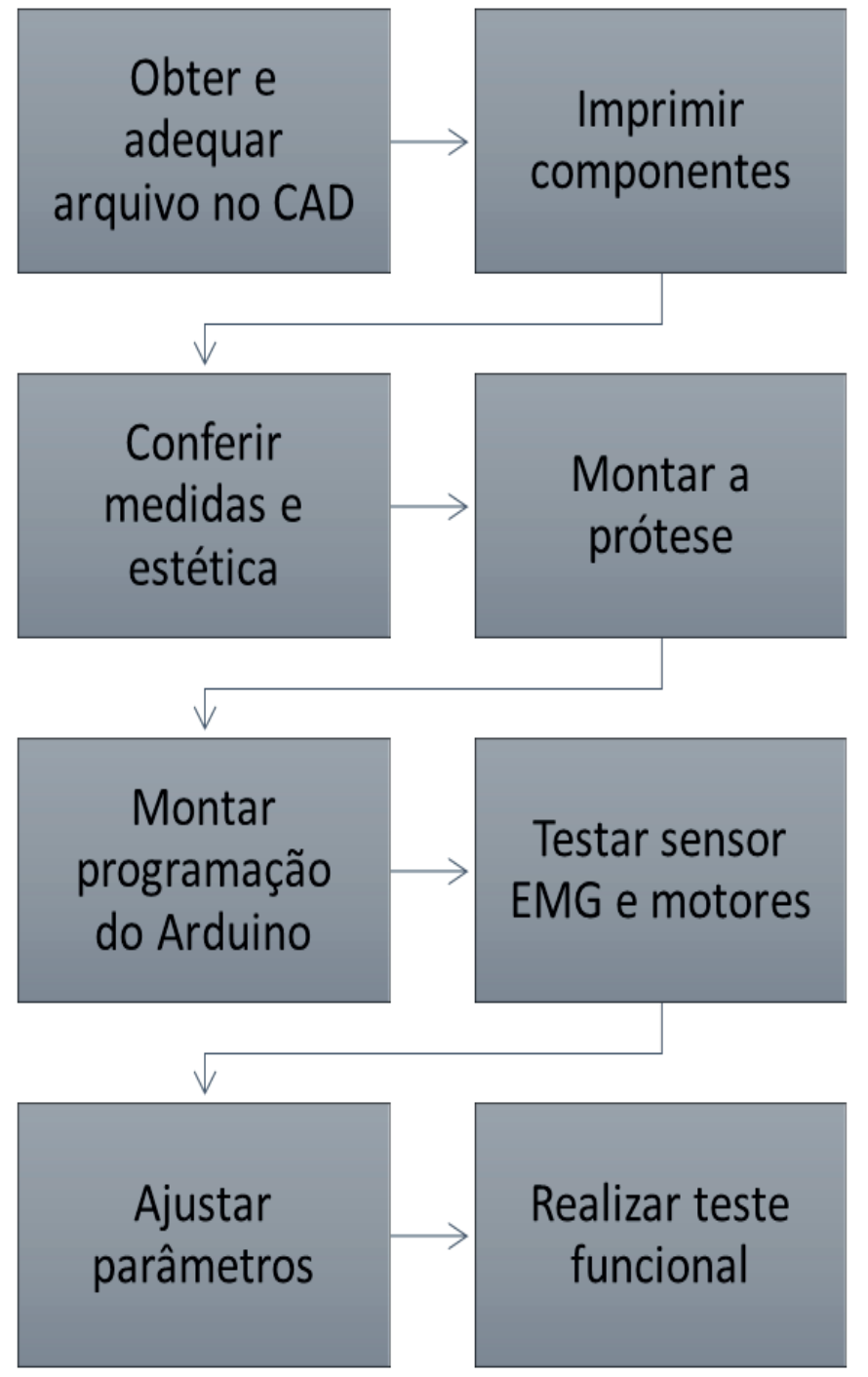

Figure 1. Activity planning

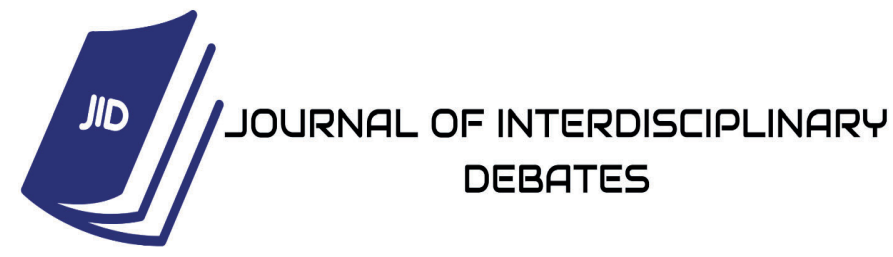


ISSN: 2675-469X

Vol. 02 - n 02 - ano 2021

Editora Acadêmica Periodicojs

RESULTS AND DISCUSSION

As the work comprises

necessary adaptations for auto-

mation, shape changes in the mo-

del were necessary to be carried

out in the CAD (Computer Aided

Design - Computer Assisted De-

sign) environment of the referred

software.

The three-dimensional model was built in parts, simulating the joints necessary for the prosthesis to perform movements similar to those of a biological limb, but also assuming the con dition of being a mechanical artifact provided with actuators and transmission elements. Thus, the modeling step comprised the simulation of the assembly of these resources, with their shapes, volume and clearances allowed. Figure 2 shows this step, with the model being designed.

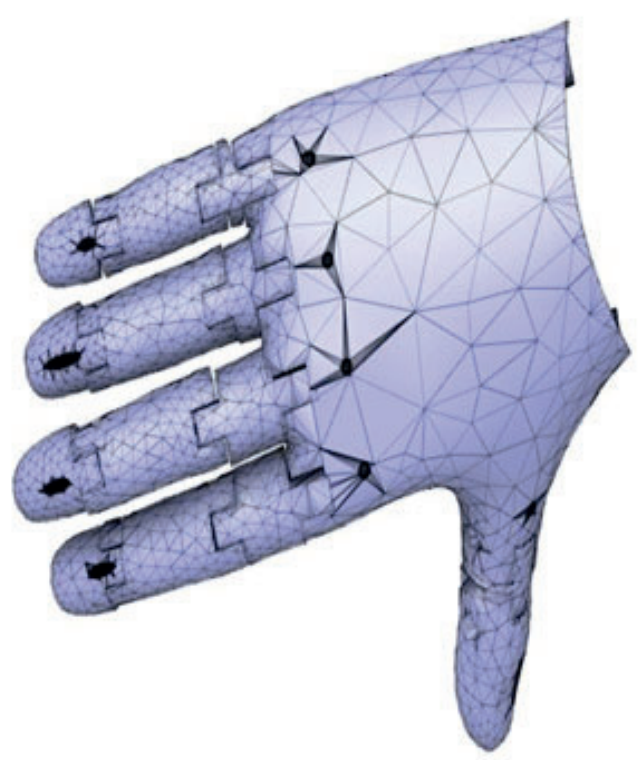


Figure 2. Computational design of the prosthesis

To manufacture the hand prosthesis, polymeric components were manufactured using additive manufacturing or $3 \mathrm{D}$ printing. The components were individually made for later assembly. It was necessary to check measurements of each piece, checking the consistency between the projected and the obtained in the printing, in addition to small adjustments, such as removal of small burrs.

In the assembly stage, as the structure was made in individual parts, $3 \mathrm{~mm}$ steel screws were used in the joints to allow movements to be carried out. The ends of these screws are provided with self-locking nuts, in order to keep them in place, but they can be removed with a little effort if disassembly is necessary at some point in the future tests.
After the assembly of the structure, the motors were inserted and, in order to connect the wires between the motors and the ends of the distal phalanges, it was necessary to make a set of gears for fixing these wires, the arcs of rotation of the gears are compatible with the length of wire that must be retracted to allow total closing of the fingers. Figure 3 shows how the prototype has already been assembled.

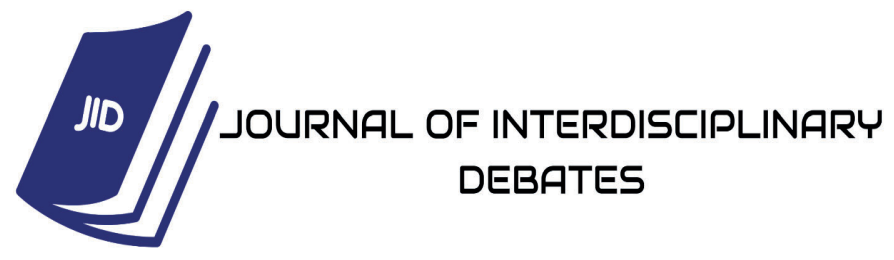




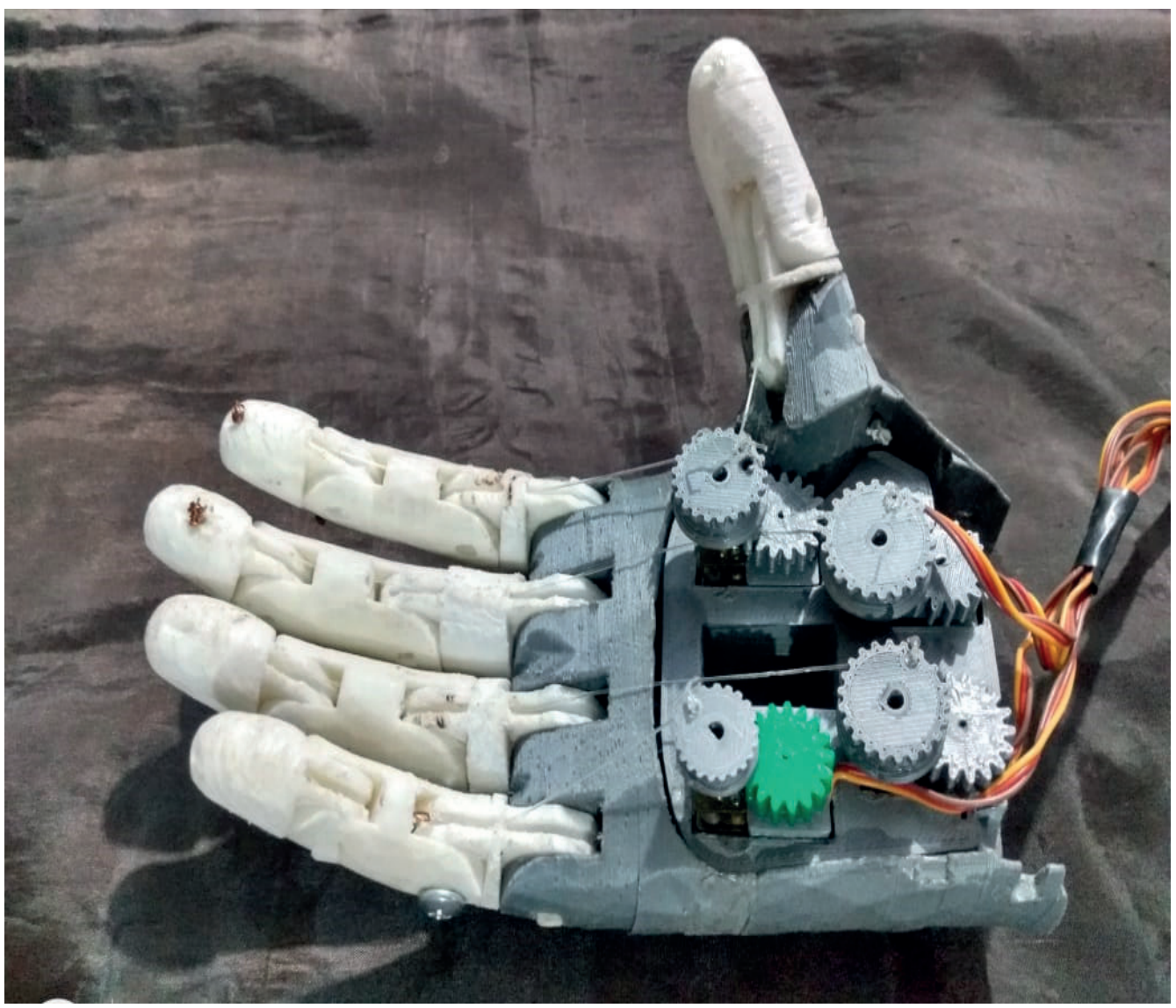

Figure 3. Prototype assembled

The functioning of the with the initial relaxation posimotors assembled and connected tion and with full contraction of to the control board was tested to the fingers in the position of the verify the degree of rotation and driven motors. Eventually, small the compatibility with the neces- adjustments in the tension of the sary freedom so that the fingers wires were considered to elimihave adequate movements. In nate any fraction of false movethis step, the gears were positioned so as to allow maximum

The functional tests angular displacement, coinciding ment. consisted of two phases: with di-

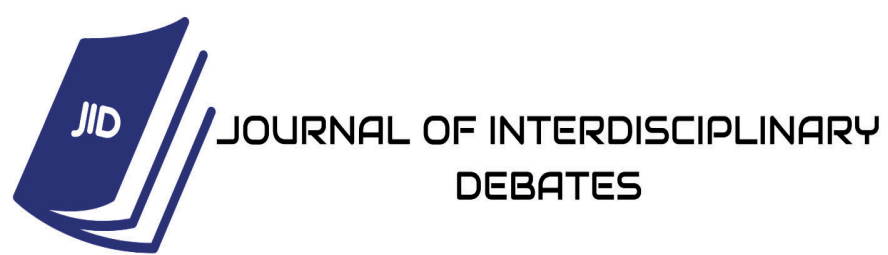


ISSN: 2675-469X

Vol. 02 - n 02 - ano 2021

Editora Acadêmica Periodicojs

rect command via program and

with parameterized command for bioelectric signal.

In the first phase, without the EMG sensors, the repeatability of the movements commanded via the terminal by the programmer was verified. The times elapsed between the trigger point and the completion of the contraction and relaxation movements were collected individually, in a series of five complete repetitions (forward and return), using a manual stopwatch. The times of each movement and the average of these values are shown in table 1

\begin{tabular}{|c|c|c|}
\hline Sequence & $\begin{array}{l}\text { Movement } \\
\text { type }\end{array}$ & $\begin{array}{l}\text { Movement } \\
\text { duration } \\
\text { (seconds) }\end{array}$ \\
\hline \multirow{2}{*}{1} & Contraction & 2.59 \\
\hline & Relaxation & 2.56 \\
\hline \multirow{2}{*}{ two } & Contraction & 2.57 \\
\hline & Relaxation & 2.59 \\
\hline \multirow{2}{*}{3} & Contraction & 2.56 \\
\hline & Relaxation & 2.57 \\
\hline \multirow{2}{*}{4} & Contraction & 2.59 \\
\hline & Relaxation & 2.57 \\
\hline \multirow{2}{*}{5} & Contraction & 2.59 \\
\hline & Relaxation & 2.56 \\
\hline \multicolumn{2}{|c|}{$\begin{array}{l}\text { Average time per } \\
\text { movement }\end{array}$} & 2.57 \\
\hline
\end{tabular}

Table 1. Movement times without sensors

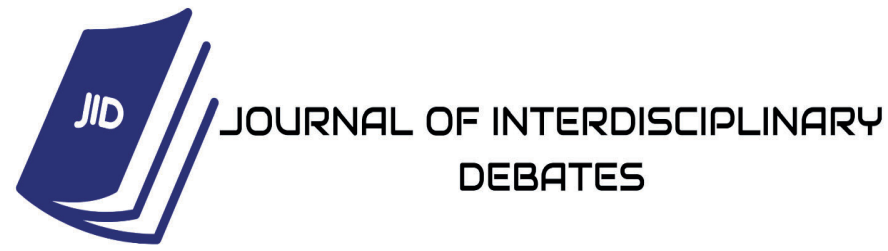


ISSN: 2675-469X

Vol. 02 - n 02 - ano 2021

Editora Acadêmica Periodicojs

In the second phase of the functional tests, the control system starts the motors from the processing of signals received by electromyography sensors. The connections of the sensors were connected to the control board, and after checking the safety of the current passing through the circuit, a volunteer received the adhesive sensors installed on the skin of the forearm corresponding to the position of the prosthesis (right side), as shown in the figure 4 . The collection of times with the stopwatch needed to be guided by the volunteer, verbalizing the instant when he started each movement to start the count and stop when each movement of the prosthesis ended.

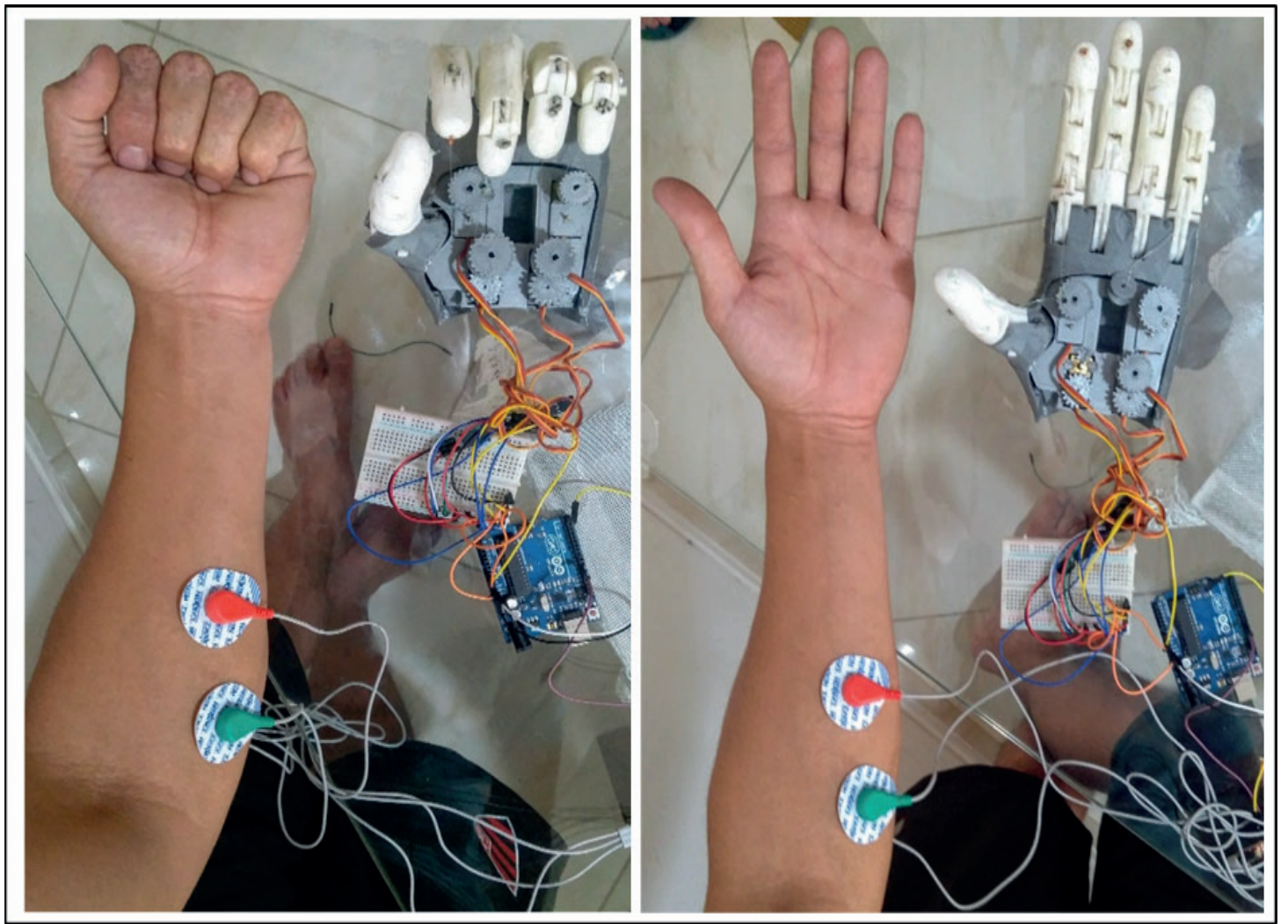

Figure 4. Test with sensors

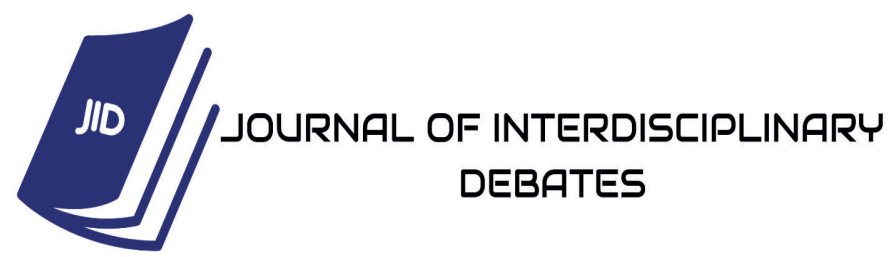


In this test, the five col-

lections were also made. The ti-

mes of each contraction and re-

laxation movement for the sensor

test are shown in table 2

\begin{tabular}{clc}
\hline Sequence & $\begin{array}{l}\text { Movement } \\
\text { type }\end{array}$ & $\begin{array}{c}\text { Movement } \\
\text { duration } \\
\text { (seconds) }\end{array}$ \\
\hline \multirow{2}{*}{1} & Contraction & 1.28 \\
& Relaxation & 1.29 \\
two & Contraction & 1.26 \\
& Relaxation & 1.35 \\
3 & Contraction & 1.47 \\
\multirow{2}{*}{4} & Relaxation & 1.36 \\
& Contraction & 1.29 \\
\multirow{2}{*}{5} & Relaxation & 1.30 \\
& Contraction & 1.26 \\
& Relaxation & 1.28 \\
\hline \multirow{2}{*}{ Average time per } & 1.31 \\
\hline
\end{tabular}

Table 2. Test with EGM sensors.

There was a shorter mo- previous test had been carried vement time in all sequences perout with a pre-defined time to formed in this step compared to act from the signal emitted at the the previous step. This phenometerminal and the latter obeys the non occurs due to the programbioelectric signals of the volunmed parameterization, since the teer. This may also explain why there is a greater dispersion in the 
ISSN: 2675-469X

Vol. 02 - n 02 - ano 2021

Editora Acadêmica Periodicojs

observed values, as the behavior of the prosthesis approaches the bionic function in response to the signals emitted by the volunteer, which are not mechanically standardized.

The functional hand prosthesis, powered by bioelectric signals and controlled by Arduino $\AA$, made using the additive manufacturing method, proved to be applicable for use by individuals who have congenital disabilities or loss of the limb due to an accident or illness. The method used for modeling and fabrication in CAD / CAM (Computer Aided Manufacturing) allows customization of the artifact, since the region of connection between the prosthesis and the end of the stump can be anatomically adjusted, in addition to allowing adjustments in the dimensioning and symmetry with the opposite side member.
Small contour adjust-

ments and an appropriate coating can easily be incorporated into custom designs as an aesthetic function.

The speed of response and the freedom of the movements performed may allow the performance of some simple tasks, but these functions were not tested in this study.

\section{CONCLUSION}

The process proved to be efficient to meet a demand that may exist for this type of rehabilitation, as it was found that it is possible to manufacture hand prostheses with automatic movement using customized additive manufacturing, that is, adapted to the situation of each user. Arduino ${ }^{\circledR}$ programming worked as expected, giving autonomous movement to an originally mechanical prosthesis. And

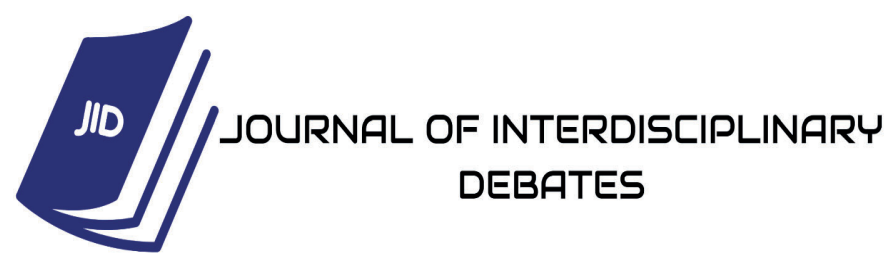


the repeatability of this process (modeling, manufacturing, programming and use) depends only on material resources, such as equipment, software and inputs, and technical knowledge, therefore already possible.

\section{THANKS}

We thank Professor Dr. José Aguiomar Foggiatto, for making the original CAD model available. And to UniOpet, which provided installation and equipment for making the prototype.

\section{REFERENCES}

Franchetti, SM Martins; Marconato J. Carlos. Biodegradable polymers - a partial solution to reduce the amount of plastic waste. New Chemistry, vol. 29, number of pages, 2006.

Foggiatto, J. Aguiomar; Silva, J. Vicente Lopes da. 3D geometric representation for AM. In: Volpato, Neri. Additive manufacturing: 3D printing technologies and applications. São Paulo: Blucher, 2017. Chap. 4, p. 69-93.

Stoppa, Marcelo H ;; Carvalho, João Carlos Mendes; Kinematic modeling, motion simulation, construction and control of hand prosthesis for manipulation tasks. In: Mathematics applied to industry: problems and methods of solution. São Paulo: Blucher, 2016. Ch. 8 p. $183-208$ Aquino, Mariana; Volpini, Mariana. Prostheses: evolution, innovation and paradigm break. Available in:www.researchgate. net/publication (2018). 